Yielding behavior and traffic conflicts at cyclist crossing facilities on channelized right-turn lanes

Peer-reviewed author version

VAN HAPEREN, Wouter; DANIELS, Stijn; DE CEUNYNCK, Tim; Saunier, Nicolas; BRIJS, Tom \& WETS, Geert (2018) Yielding behavior and traffic conflicts at cyclist crossing facilities on channelized right-turn lanes. In: TRANSPORTATION

RESEARCH PART F-TRAFFIC PSYCHOLOGY AND BEHAVIOUR, 55, p. 272-281.

DOI: 10.1016/j.trf.2018.03.012

Handle: http://hdl.handle.net/1942/26096 


\section{YIELDING BEHAVIOR AND TRAFFIC CONFLICTS AT CYCLIST CROSSING FACILITIES ON CHANNELIZED RIGHT-TURN LANES}

3

4

5 Wouter van Haperen $^{\mathrm{a}^{*}}$, Stijn Daniels ${ }^{\mathrm{a}, \mathrm{b}}$. Tim De Ceunynck ${ }^{\mathrm{a}, \mathrm{b}}$, Nicolas Saunier ${ }^{\mathrm{c}}$, Tom Brijs ${ }^{\mathrm{a}}$, Geert 6 Wets $^{\mathrm{a}}$

7

$8{ }^{a}$ UHasselt, Transportation Research Institute (IMOB), Agoralaan, 3590 Diepenbeek, Belgium

$9 \quad{ }^{\mathrm{b}}$ Vias Institute, Haachtsesteenweg 1405, 1130 Brussels, Belgium

$10{ }^{\mathrm{c}}$ Department of Civil, Geological and Mining Engineering Polytechnique Montréal, C.P. 6079, 11 succ. Centre-Ville Montréal (Québec) Canada H3C 3A7

12

$13 *$ corresponding author: wouter.vanhaperen@uhasselt.be

14

15

16 


\section{ABSTRACT}

2 Channelized right-turn lanes (CRTLs) improve traffic flow efficiency, enabling right-turning 3 drivers to bypass traffic lights at signalised intersections (for right-hand drive countries). Many 4 CRTLs provide crossing facilities for pedestrians and cyclists. Previous studies examining the 5 safety performance of CRTLs indicate that they increase overall safety levels but hint that safety 6 issues regarding vulnerable road users exist. This study investigated these issues through 7 site-based observations of yielding behavior and evaluated the effect of the priority rule on 8 cyclists' safety in two CRTL designs. Four locations in Belgium were selected for video 9 observations: two where the priority rule favoured cyclists and two where motorists had priority.

With regard to yielding, four types of crossing behavior were identified and defined. Independent of the priority rule, cyclists crossed the conflict zone first in most interactions without taking the initiative to cross first. Underlying reasons for motorists willingly giving away their right-of-way could not be determined, but possible courtesy or fear of inflicting injuries at vulnerable road users might be at hand. A safety evaluation was performed using two traffic conflict indicators TTC $_{\min }$ and the TA value). High correlations between the two indicators were found $\left(r^{2}>0.83\right)$, but no conclusions about the safest priority rule for cyclists could be drawn. The results hinted, however, that locations with motorist priority and cyslists crossings from right to left (from the driver's point of view) yields the highest proportion of safety critical events.

Keywords: Channelized right-turn lanes, Priority ruling, Traffic conflicts, Surrogate measures of safety, Yielding behavior 


\section{INTRODUCTION}

Several right-turn treatments exist to improve traffic flow efficiency at signalised intersections. Examples include exclusive right-turn lanes, right-turn-on-red rules and channelized right-turn lanes (CRTLs) (AASHTO, 2011). CRTLs offer drivers a more comfortable right-turn movement by allowing them to bypass traffic lights and stop only when it is really necessary. In many cases, CRTLs include crossing facilities for cyclists as well, but their design varies between intersections. In general, two types of cyclist crossings at CRTLs can be distinguished: one where cyclist crossings are located at the entrance and the exit of the CRTL and another where the cyclist crossing is located at the centre of the CRTL (Figure 1). The main difference between the two configurations is that when there are crossings at both the entrance and exit, these are usually unidirectional, while a crossing facility at the centre of the turning lane allows cyclists and mopeds to cross in both directions. CTRL design guidelines and regulations in Flanders are not clear as to which configuration should be used in which situations, and rules are lacking regarding how priority rules in centre-crossing designs should be applied by road designers. As a result, there is no uniformity in CRTL design and this creates varying, unclear and possibly unsafe situations for cyclists and motorists. To our knowledge, no international literature has investigated the influence of priority rules on yielding behavior and cyclists' safety at cyclist crossings at CRTLs. Therefore, and on request of the Flemish Road Agency, this study investigates the yielding process between drivers and cyclists and provides insights into the safety issues that occur at the centre-crossing design CRTL, including an evaluation of the effects of the priority ruling at hand.

FIGURE 1 The two configurations for accommodating vulnerable road users on CRTLS (modified from Potts et al, 2011).

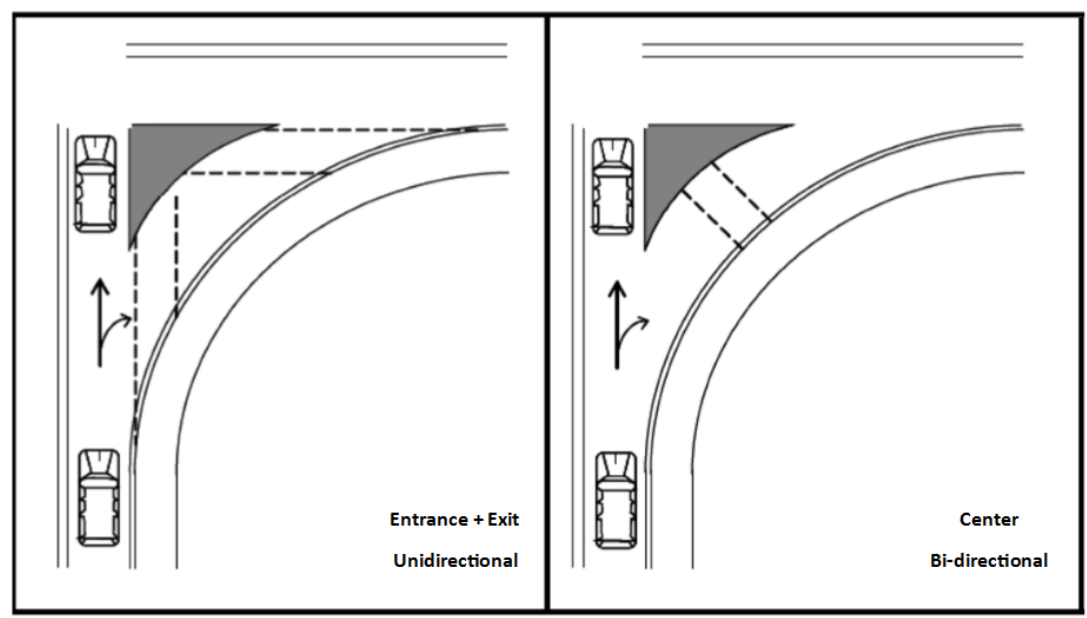

Many transportation agencies perceive CRTLs to improve traffic safety levels (Potts et al., 2013), but quantitative data supporting this statement is limited. Most studies investigating the safety performance of CRTLs have focused on motorists and on the comparison of different right-turn treatments. For example, Dixon et al. (1999) compared intersections with shared through lanes (one lane accommodating traffic both going straight and turning right) and right-turn lanes with and without raised islands in Georgia (USA) and found that the presence of traffic islands decreased the number of right-angle crashes. A similar study in Texas (USA) concluded that shared through lanes experienced fewer crashes than right-turn lanes (Fitzpatrick et al, 2006). A Belgian study evaluated 1,295 crashes at 87 signalised intersections and concluded that intersections with CRTLs have fewer accidents (Polders et al., 2015). However, an increase in the number of rear-end collisions was found; this was attributed to yielding behavior towards 
vulnerable road users and searching behavior for finding an appropriate gap to merge into the traffic stream. Autey et al. (2012) compared two types of CRTL designs in Canada and concluded, based on traffic conflict observations, that sharper turning angles at the convergence point may result in more potentially dangerous situations.

Although several studies suggest that conflicts between motorists and vulnerable road users may occur, scientific research focusing on cyclists' and pedestrians' safety issues at CRTLs is limited. Several researchers hinted that drivers focus mainly on motorists driving on the road that they are about to merge into rather than on the potential presence of pedestrians and cyclists (Potts et al., 2011; Potts et al., 2013; Fitzpatrick et al., 2006; Polders et al., 2015). In these cases, drivers may see approaching vulnerable road users but are unable to detect them, succumbing to the "looked-but-failed-to-see" error (Hersland and Jørgensen, 2003). Additional problems occur on bidirectional crossings, because drivers might not expect cyclists to arrive from their right-hand side. Potts et al. (2013) compared conventional right-turn lanes, shared through lanes and CRTLs and found that conventional right-turn lanes experienced $70-80 \%$ more pedestrian crashes; however, no differences were found between the other two right-turn treatment types. Sayed et al. (2013) conducted a video observation study in Canada that investigated both motorists' and cyclists' safety and found that cyclists' safety was mostly threatened by motorists ignoring yield signs and blocking the cyclist crossing facility. However, no study could be found that specifically looked into the effect of different priority rules at cyclist crossing facilities at CRTLs. Therefore, this study further investigated cyclists' safety issues at these crossing facilities.

\section{OBJECTIVES}

Previous studies have focused on the road safety performance of channelized right-turn lanes with regard to motorised road users. However, little is known about safety issues for vulnerable road users. The present study is designed to identify the behavior of drivers and cyclists during the yielding process at CRTLs. The main objective of this study is to improve understanding of cyclists' safety at CRTLs, focusing specifically on the influence of the priority rule. For this purpose, real-world observations were conducted at four CRTLS to assess yielding behavior and to study traffic conflicts distinguishing between the priority rule at hand. For brevity, when we refer to cyclists, this group also includes moped riders unless otherwise stated.

\section{METHODOLOGY}

On-site observations of road users' yielding behavior and of occurring traffic conflicts were applied to investigate the safety of cyclists' at CRTLs. Although the validity of traffic conflict techniques has not yet been fully determined, empirical evidence suggests a strong correlation between the frequency of traffic conflicts and accidents (e.g. Sayed et al., 2013; Hydén, 1987; Svensson and Hydén, 2006; Sayed and Zein, 1999; El-Basyouy and Sayed, 2013). Furthermore, traffic conflict observations have already been used for safety evaluations at CRTLs and have shown to lead to useful insights into their safety performance (e.g. Autey et al., 2012; Sacchi and Sayed., 2013; Sayed et al., 2013).

The Flemish Road Agency (AWV) provided a list of existing CRTL locations in Flanders, Belgium. Based on the configurations (Figure 1) and design elements (intersection crossing angle, form of the curve, speed limits, raised platforms, zebra crossings), four locations were selected for a cross-sectional research design. Cyclists had the right-of-way at two of these locations, while motor vehicle drivers had the right-of-way at the two other locations. All locations accommodated cyclists crossing in both directions. None of the locations had a raised platform. Two locations (one of each type of priority rule) included a zebra crossing, where pedestrians are required to cross the CRTL (for locations without a zebra crossing, pedestrians are supposed to use the cyclist 
crossing facility). It is worth mentioning that pedestrians always have the right-of-way at a zebra crossing, even in case the adjacent bicycle crossing did not. For both pairs (with a zebra crossing and without), one gave cyclists priority and the other gave motorists priority using yielding signs and shark's teeth yielding lines.. At each location, two video cameras were used to observe yielding behavior. One of the cameras was located at the approaching leg, approximately 50 meters from the cyclist crossing; this enabled the capture of relevant road users' approaching behavior. The second camera was mounted closer to the crossing facility in order to gather accurate distance and speed measurements (Figure 2). The cameras recorded continuously between the $11^{\text {th }}$ and $17^{\text {th }}$ of June 2015 . Because of the low volumes of cyclists during night time, only daytime hours (06:00 - 21:00) were analysed.

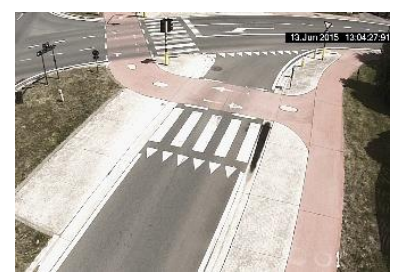

$\mathrm{C}(\mathrm{Z})$

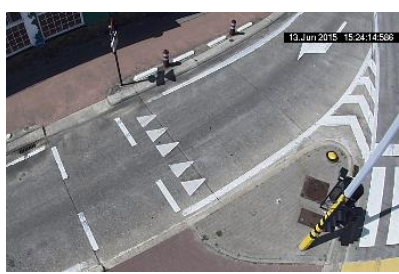

$\mathrm{C}$

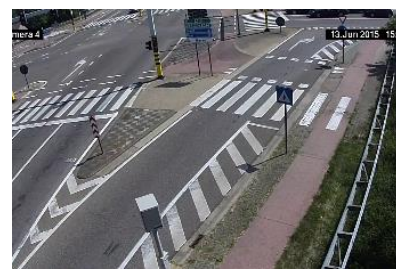

$\mathrm{M}(\mathrm{Z})$

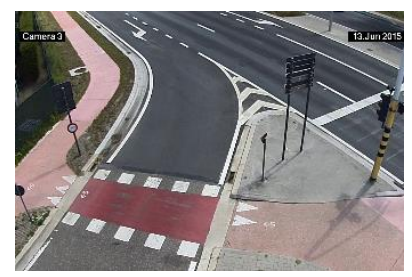

$\mathrm{M}$

FIGURE 2 The four CRTLs observed in this study. Locations are named based on priority ruling (either cyclists $(C)$ or motorists $(M)$ have right-of-way) and the presence of a zebra crossing $(\mathbf{Z})$.

Interactions between cyclists and motorists were manually retrieved from video data and then processed using the semi-automated video analysis tool T-Analyst (T-Analyst, 2014). This software transforms image coordinates of pixels to road plane coordinates and then lets the user manually annotate the road users' trajectories, which enables the accurate calculation of speeds and distances. From these, the software calculated the traffic conflict indicators in an accurate and objective manner based on motion prediction at constant speed and direction.

\subsection{Traffic events}

With regard to traffic events, the classification depicted in Figure 3A is taken from the road safety hierarchy popularised by Hydén (1987). The figure provides a schematic overview of the relative frequency in which these different events occur, but the proportions are purely illustrative and do not necessarily reflect their relative frequency or occurrence in traffic. The different event types can be described as follows:

- The 'all traffic events' category represents all situations in which at least one road user is present at the CRTL crossing facility.

- 'Passages' are events in which two road users are simultaneously present near the crossing facility. 'Simultaneously' in this study is operationalised as the motorist being captured on the camera closest to the crossing facility and the cyclist being within 10 meters of the centre of the crossing facility at the time of the motorist's approach. This event type includes situations in which the cyclist crossed the projected path of the motor vehicle (defined as 'interactions' and described below), as well as situations in which the cyclist did not cross the path of the motor vehicle ('no crossing' events, the dashed arrow in Figure 3B).

- All 'passages' in which cyclists and motorists cross at the crossing facility simultaneously are labelled 'interactions' (the solid arrow in Figure 3B). During these events, drivers and cyclists need to react to and/or communicate with each other in order to cross safely. 
- 'Conflicts' are interactions that comply with the definition proposed by Amundsen and Hydén (1977): 'An observable situation in which two or more road-users approach each other in space and time to such an extent that a collision is imminent if their movements remain unchanged'.

- 'Accidents' are collisions between two or more road users.

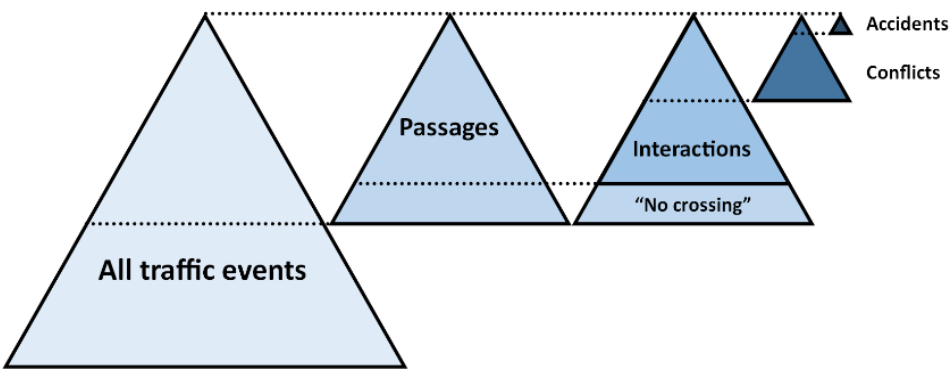

A

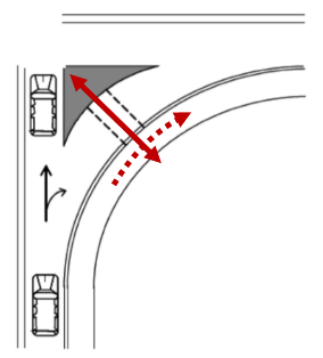

B

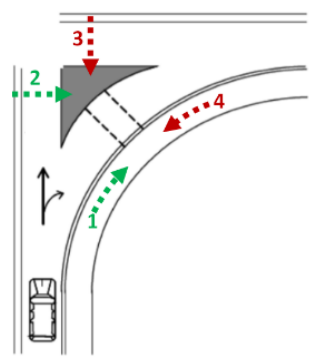

C

FIGURE 3 A) the classification of events, B) the difference between 'interactions' (solid line) and 'no-crossing' events (dashed line) and $\mathrm{C}$ ) the four arrival directions.

Figure $3 \mathrm{C}$ shows the possible directions of arrival at the cyclist crossing facility. With the exception of one of the locations, cyclists were not allowed to arrive at the crossing facility from directions 3 and 4, due to unidirectional cycle infrastructure. For the fourth location, however, a crossing in direction 2 was not constructed, resulting in a bidirectional crossing facility in direction 3. Since the share of interactions involving pedestrians was small (8\%), all events including pedestrians were excluded. Furthermore, in case cyclists crossed in group, only the leading cyclist was considered in the analyses. When two cyclists were traveling right next to each other, the cyclists closest to the motorists was considered. No interactions were found in which cyclists arrived simultaneously at the crossing facility from both the left and right side.

\subsection{Yielding behavior}

Interactions rather than passages were analysed, since crossing is a prequisite for yielding. The classification of yielding behavior proposed by Van Minnen and Braimaister (1994) was used and modified to describe crossing behavior. Based on rule compliance ('Does the road user that has priority go first?') and crossing style ('Does the road user that goes first take the initiative?'), the following four types of yielding behavior are defined:

- Taking: The road user that has priority goes first while forcing the other road user to let him go first. This can occur when both road users arrive simultaneously at the crossing facility: the prioritised road user does not slow down, thereby forcing the other to reduce speed. This type can also occur when the prioritised road user arrives first at the crossing facility, stops for a certain reason and starts to cross while another road user is approaching.

- Getting: The road user that has priority goes first without forcing its right-of-way. This type of crossing occurs when a) the road user that should yield arrives first and has time to cross but slows down and yields anyway, $b$ ) when both road users arrive at the same time but the one that should yield willingly slows down and yields (the start of the (right-turn) curve itself was regarded as transition point between 'taking' and 'getting' the right-of-way: if motorists slowed down before the passed this point, crossing was regarded as 'getting') or c) when the road user that has priority is waiting for a safe opportunity to 


\subsection{Traffic conflict analyses}

cross and the approaching road user that should yield slows down to let him cross first. In all these cases the priority rule is not violated.

- Forcing: The road user that should yield does not slow down or stop to yield, either forcing the other road user to stop or failing to stop when the prioritised road user is waiting for a safe opportunity to cross.

- Receiving: The road user that has priority willingly gives it away. Examples of identifying this behavior include the flashing of headlights by drivers or a cyclist waving a driver to pass first. Strictly speaking, this behaviour is not correct, since the priority rule is being violated.

Two traffic conflict indicators derived from the Time-To-Collision (TTC) were used to evaluate safety aspects. This indicator calculates the time that is left until a collision will occur, if all involved road users maintain their current speed and direction (15). The TTC is a continuous variable as long as road users are on a collision course. In order to describe conflict severity, a single value of this TTC-value can be selected. The DOCTOR technique proposes using the minimum value of the TTC as a measure for conflict severity. Within urban environments, TTC $_{\min }$ values less than 1.50 seconds represent safety critical situations (Kraay et al., 2013). The Swedish Traffic Conflict Technique on the other hand proposes to use the TTC value at the moment an evasive action by either one of the road users is performed. Conflict severity is then determined by allocating a severity level, based on the conflicting speed and TTC-value of the moment the evasive action is performed. Svensson and Hydén (2006) and Laureshyn et al. (2016) describe that severity level 26 distinguishes between slight and serious conflicts. However, they argue that for conflicts involving vulnerable road users, a lower threshold could be used because vulnerable road users have lower speeds and are often the first to take evasive action, resulting in systematically lower scores. Therefore, and comparable to Laureshyn et al. (2016), conflicts with a severity level of 24 or higher were considered serious in this research.

\section{RESULTS}

\subsection{Yielding Behavior}

Crossing behavior was analysed for all interactions based on the definitions formulated in section 3.1. The analyses distinguished between cyclists' crossing direction (Figure 5). The following important observations were made:

- Independent of the priority rule or the crossing direction, cyclists crossed first in more than $80 \%$ of the cases ('taking' and 'getting' for the $\mathrm{C}(\mathrm{Z})$ and $\mathrm{C}$ locations, 'forcing' and 'receiving' for the $M(Z)$ and $M$ locations), except for the $M(Z)$ location.

- When crossings occurred from left to right (from the perspective of the approaching driver), cyclists crossed first more often $\left(\chi^{2}=158.875\right.$, df $\left.=1, \mathrm{p}=.000\right)$.

- The proportions of cyclists' initiative taking behavior was higher when cyclists crossed from left to right $\left(\chi^{2}=19.779, \mathrm{df}=1, \mathrm{p}=.000\right)$.

- For three locations, the majority of cyclists did not take initiative during events in which they crossed first.

- When cyclists crossed from right to left, motorists forced priority (at $\mathrm{C}(\mathrm{Z})$ and $\mathrm{Z}$ ) more often compared to cyclists crossing from left to right.

- The M (Z) location showed clearly different results when cyclists crossed from right to left. This might be explained by the fact that in $68 \%$ of the interactions in which cyclists 
crossed from right to left, the cyclist arrived at the crossing facility while cycling in the opposite (and illegal) direction (direction 4 in Figure 3C). Drivers might not expect cyclists to arrive from that direction and therefore may not actively look for them. At the same time, because they cycle in this illegal direction, cyclists might approach with more caution, resulting in more yielding.

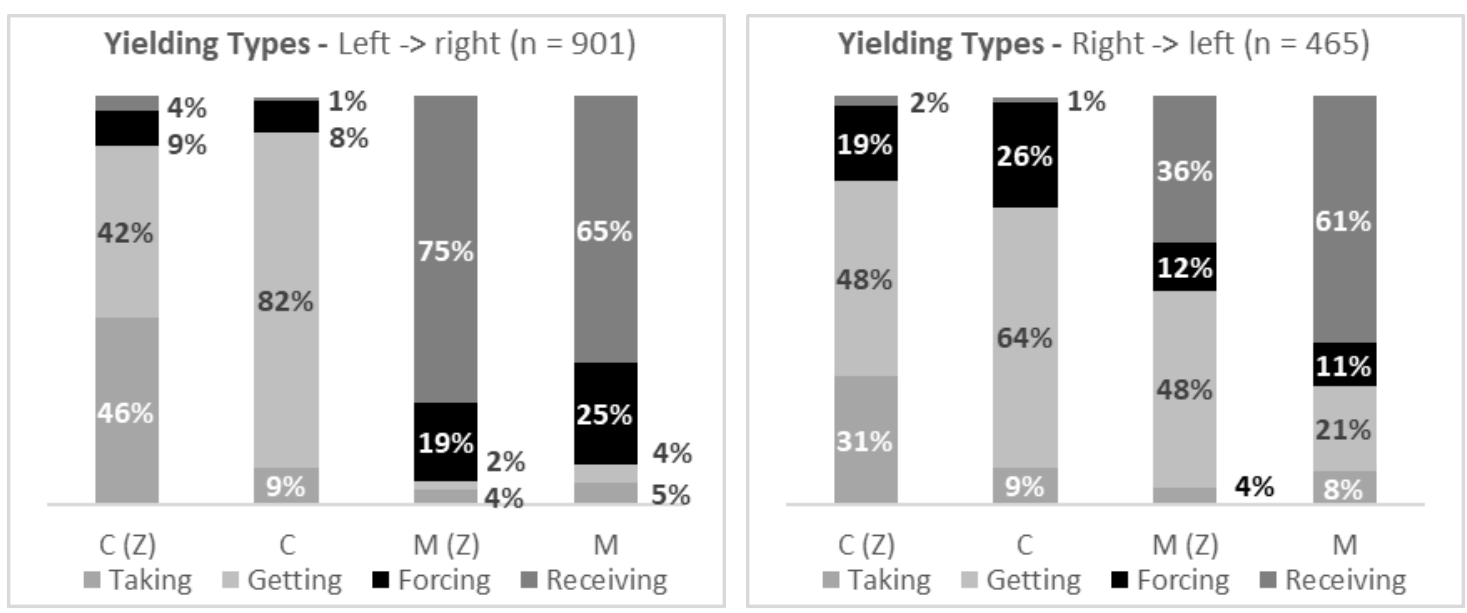

FIGURE 4 The yielding types per location. 'Taking' and 'getting' align with the priority rule.

\subsection{Traffic conflict analysis}

\subsubsection{TTCmin}

A TTC value was calculated for a total of 387 events. For each conflict, the minimum value of the TTC was registered and then grouped into increments of 0.10 seconds. For all locations, the proportion of serious conflicts (based on a threshold level of 1.50 seconds) did not exceed $15 \%$ of all conflicts and amounted to 23 events in total. Cumulative distributions were plotted but only revealed differences when there was a distinction in the crossing direction (Figure 5, top). Serious conflicts occurred more often when cyclists crossed from right to left, but the most critical values were found for the other crossing direction (the lowest values found for crossing left to right were 0.91 and 0.97 compared to 1.23 ) for crossing right to left.

\subsubsection{Time-to-accident value}

In total, evasive actions for 93 conflicts were identified; the resulting conflicting speed and TA severity levels are plotted in Figure 5 (middle). In many cases, both road users performed an evasive action. For these situations, the severity level of the road user that produced the least severe conflict (the relevant road user) was selected (Shbeeb, 2000). For half of the cases, the cyclist was identified as the relevant road user, with the exception of location $\mathrm{C}$ (30\%). Roughly $50 \%$ of the observed conflicts had a severity level of at least 24, resulting in 43 serious conflicts in total. The most critical safety level found was 26 , which occurred three times at a location where cyclists should yield. Similar to the findings of the $\mathrm{TTC}_{\min }$ indicator, it was observed that the proportion of serious conflicts for crossing right to left was higher compared to the other direction (67\% (9 out of 12) vs $43 \%$ (35 out of 81$)$ ), but that this difference was not significant $\left(\chi^{2}=2.313\right.$, $\mathrm{df}=1, \mathrm{p}=.128)$. Higher proportions of serious conflicts for this crossing direction were also found when only events with a severity level of at least 25 and 26 were considered (25\% vs $10 \%$ and $17 \%$ vs $1 \%$, respectively). It was also observed that with regard to crossing from right to left, only three serious conflicts were found for locations where cyclists have priority and six for locations where 
motorists have the right-of-way.
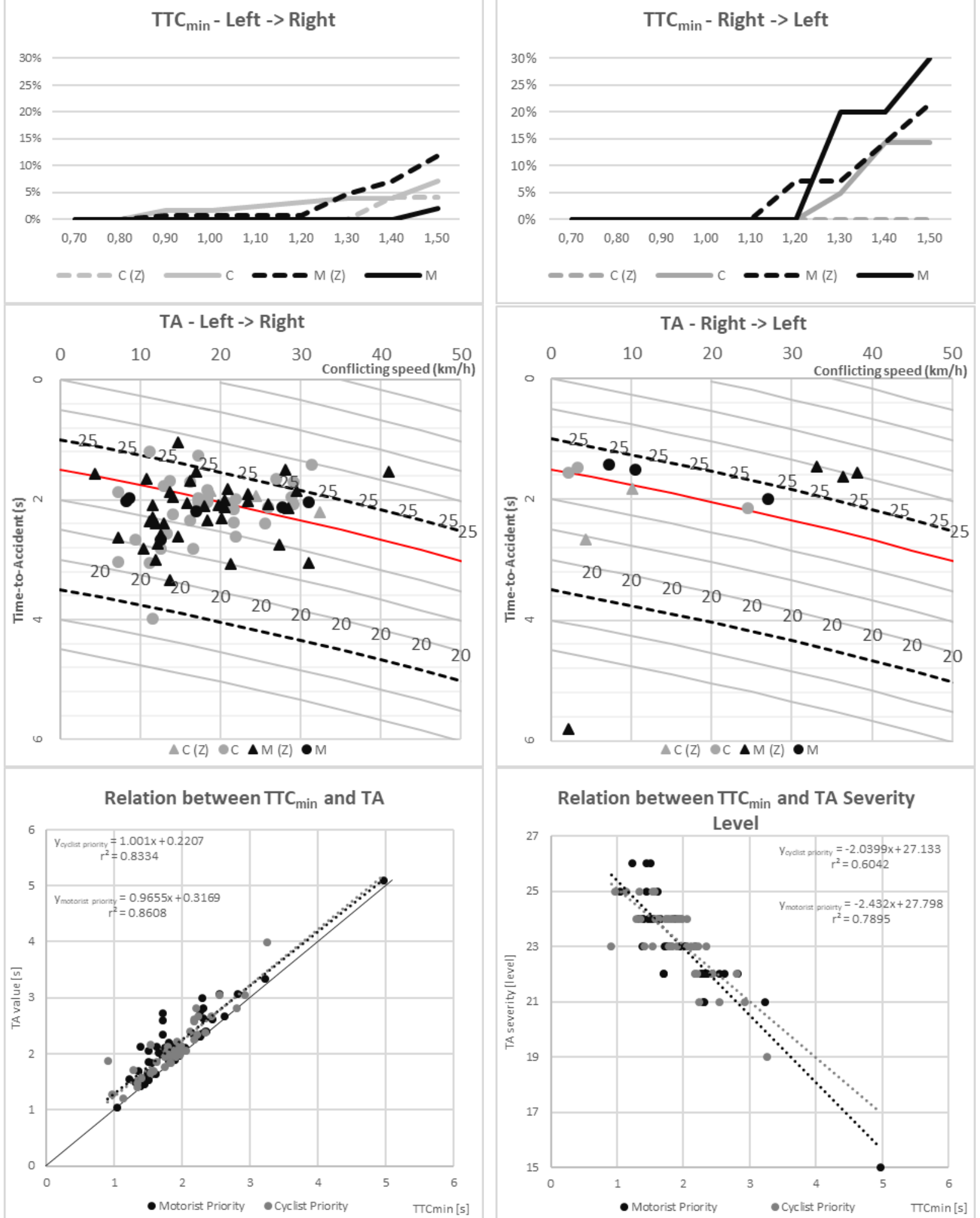

FIGURE 5 On top, the cumulative distributions of the conflicts identified by the TTC $_{\min }$ indicator. In the middle, conflicts identified by the TA-value. Below, the comparison between the TTC $_{\min }$ and TA-value (left) and between the TTC $_{\min }$ and TA severity level (right). The equations are shown in the top left and right corners. 


\subsubsection{Comparison between conflict indicators}

Due to their differing characteristics, the number of conflicts identified by the two indicators differed. The $\mathrm{TTC}_{\min }$ can be calculated for every situation in which road users were (at some point) on a collision course, while the TA value can only be determined if at least one of the road users performed an evasive action. As a consequence, all conflicts with a TA value also had a $\mathrm{TTC}_{\min }$ value, but not vice versa. In total, 93 out of the 387 events contained values for both indicators. The overlapping conflicts were examined in more detail in order to examine the relationship between the TA value and the $\mathrm{TTC}_{\min }$ indicator. Figure 5 (bottom) presents a scatterplot containing the 93 conflicts and their corresponding $\mathrm{TTC}_{\min }$ and TA values. Only five conflicts had identical values for both indicators; the remaining 88 conflicts had higher TA values (by an average of $0.23 \mathrm{~s}$ ). This is expected: when an evasive action is taken, the road users involved still approach each other in both space and time. The effect of the evasive action is that the TTC value will reduce at a lower rate until a certain minimum is reached, and the TTC value will increase and eventually cease to exist when the collision course has been eliminated. Linear regression equations were created for both priority rules, showing high correlations between the two indicators $\left(r^{2}>0.83\right)$.

Because the TA value does not directly relate to conflict severity (severity level is determined by the combination of the TA value and the driving speed at the start of the evasive manoeuvre), a second scatterplot showing the severity levels was created (Figure 5, bottom right). In general, lower $\mathrm{TTC}_{\min }$ values corresponded to higher severity levels, but the relationship between the two indicators is not entirely linear for the most critical safety events. Simple linear regression also indicated strong correlations between severity level and $\mathrm{TTC}_{\min }$ values for both cyclist priority $\left(r^{2}>0.60\right)$ and motorist priority $\left(r^{2}>0.78\right)$.

\subsubsection{Safety effect of the priority rule}

In order to evaluate the effect of the priority rule on cyclists' safety, a student t-test was performed. A statistically significant lower mean of the TTCmin for locations with motorist priority at the 0.10 level was found $(t=-1.677, p=0.094)$, indicating that these locations yield more critical conflicts. A comparable analysis was run for the TA value, but no statistically significant influence was found $(\mathrm{t}=0.477, \mathrm{p}=0.635)$.

\section{DISCUSSION}

\subsection{Yielding behavior}

The results show that cyclists cross first in the majority of cases, without taking the initiative. Even when motorists have the right-of-way, they willingly let the cyclist cross first. This observation is in line with the results of a Flemish study investigating yielding behavior at roundabouts (De Ceunynck et al, 2015). Studies in the scientific literature regarding the yielding of motorists for cyclists at crossings where motorists have priority were not found; this limited the opportunity to determine if these high 'courtesy' yielding rates are only part of the Flemish driving culture or are common in other countries, as well. With regard to the observations of yielding behavior at CRTLs with cyclist priority, no comparable studies were found. Sayed et al. (2013) identified the main safety issue for cyclists to be motorists ignoring the yield sign, but this conclusion was based on the analysis of traffic conflicts only. No figures of interactions with (in)correct yielding behavior were provided.

Another aspect that should be taken into account regards the arrival of direction. Cyclists approaching from directions 3 and 4 (as presented in Figure 3C) are looking straight at approaching drivers, while cyclists from directions 1 need to look backwards and the view of 
cyclists arriving from direction 2 might be occluded by queuing vehicles. It is possible that these visibility aspects influence yielding behavior and future research might investigate to what extent it alters road users' approaching behavior and descision wheter or not to yield.

\subsection{Safety evaluation}

This study used the $\mathrm{TTC}_{\min }$ and Swedish Traffic Conflict Technique to evaluate cyclists' safety at CRTL crossing facilities. The following aspects must be considered:

- The severity threshold selected to distinguish between slight and serious conflicts determines the number of serious conflicts identified. With regard to the Swedish Traffic Conflict Technique, the literature is not clear as to which severity level should be selected as the threshold level for traffic conflicts involving vulnerable road users. Furthermore, most reported traffic conflict studies have focused on interactions between motorised road users only, while vulnerable road users (including cyclists) have other capabilities to perform evasive actions (Laureshyn et al, 2016). Shbeeb (2000), for example, pointed out that pedestrians can stop almost instantaneously, while motorised vehicles cannot. Pedestrians and cyclists are far more manoeuvrable and therefore use other evasive actions to avoid collisions. However, lowering the severity threshold from level 26 to level 24 , as suggested by Svensson and Hydén (2006), might mitigate the systematically lower severity scores created by the evasive actions of vulnerable road users (Svensson, 1998; Laureshyn et al., 2016). However, more research is needed to confirm the validity of the Swedish Traffic Conflict Technique using this lower threshold value.

- Both safety indicators evaluate safety levels based on the road users involved being on a collision course. However, the occurrence of a collision course can be the result of the following situations (listed from the perspective of the driver, but also applicable from the perspective of the cyclist):

1. Road users are on a collision course throughout their entire approach, resulting in the need for at least one of them to take an evasive action to avoid a collision.

2. During the beginning of their approach, the road users are on a collision course. Because the driver has to take the right-turn curve and needs to (carefully) merge with traffic at the end of the right-turn lane, the driver reduces speed and thereby transforms the collision course into a crossing course well in advance of the crossing facility. In these cases, the initial speed reduction is not caused by the presence of the cyclist but by the curve and/or merging manoeuvre at the end of the right-turn lane. As a result, no evasive action is required of either road user.

3. During the beginning of their approach, the road users are on a crossing course. Because the driver has to take the right-turn curve and needs to (carefully) merge with traffic at the end of the right-turn lane, the driver reduces speed and thereby transforms the crossing course into a collision course. Presumably because he notices the cyclist, the driver continues to gradually reduce speed to let the cyclist pass first. In these situations, the evasive braking manoeuvre is not initiated but continued. The exact moment when braking becomes an evasive action is difficult to determine.

4. During the beginning of their approach, the road users are on a crossing course. Because the driver has to take the right-turn curve and needs to (carefully) merge with traffic at the end of the right-turn lane, the driver reduces speed and thereby transforms the crossing course into a collision course. In order to avoid collision, an 
evasive action by (one of) the road users becomes necessary (e.g. motorists increasing rather than continuing the braking force).

One could argue that the TTC value is only relevant for situations 1, 3 and 4 because during these situations road users are on a collision course as part of their 'planned' movement through the CRTL. The avoidance of a possible collision in situation 2 is the result of the speed reduction needed for motorists to drive safely through the curve and merge with traffic at the end of the turning lane and not a reaction to the presence of the cyclist. With regard to the Swedish Traffic Conflict Technique, situation 3 poses difficulties because it is nearly impossible to determine the exact moment the approaching driver reacts to the cyclist by continuing the braking manoeuvre. However, one could raise the question here whether these 'type 3' events should be labelled as slight conflicts in any case because the 'start' of the evasive action was not influenced by the (detection of) the cyclist and no new (sudden) evasive action is commenced.

- The $\mathrm{TTC}_{\min }$ indicator can be determined for all situations in which road users are (at some point) on a collision course, while the TA value requires evasive manoeuvres to detect and classify conflicts. As described in the previous point, evasive actions can only be detected in situations 1 and 4 . This might explain why for only 93 out of $387 \mathrm{TTC}_{\min }$ events a TA value could be calculated.

- The TTC value evaluates what would have happened if both road users maintained their speed and direction. For many events in our safety evaluation, the selected TTC value (either $\mathrm{TTC}_{\min }$ or TA) was taken when the road user was already reducing its speed. Therefore, the TTC at this instant may already overrepresent the severity.

\subsection{Policy recommendations}

Based on the findings, this study could not conclude which priority rule is safer for cyclists at crossing facilities at CRTLs. For situations in which cyclists crossed from left to right (from the perspective of the approaching driver), the majority of the motorists gave their priority away willingly. These high levels of courtesy yielding suggest that drivers tend to approach the crossing facility cautiously, possibly due to the complex nature of the situation itself, where motorists not only need to check for the presence of other road users but also need to select an acceptable gap to merge with the traffic stream at the end of the right-turn lane. Another possible explanation for these high rates of courtesy yielding might be that motorists are driving at a relatively low speed and due to a lack of uniformity in the application of the priority rule decide to yield to vulnerable road users anyway. The relationship between speed and yielding has previously been suggested by Bertulis and Dulaski (2014), who found that lower speeds resulted in higher yielding rates (75\% yielded at $32 \mathrm{~km} / \mathrm{h}$, only $40 \%$ yielded at $50 \mathrm{~km} / \mathrm{h}$ ). However, it may also be possible that motorists' yielding does not occur due to courtesy, but due to fear of inflincting injuries on road user types that are more vulnerable, not being aware of the priority rule and choose the safest option by letting cyclists go first or due to informal traffic rules (Björklund et al, 2005). Independent of the reasons underlying motorists' behavior to give away their right-of-way, which might be target of further research, it might be important to apply a more uniform design and/or consistency in priority rules to improve cyclists' safety at CRTL crossing facilities.

\subsection{Strengths, limitations and further research}

Further development is needed for the definitions of yielding types. Most researchers only define yielding behavior in terms of which road user crosses first (e.g. Sakshayg et al., 2010, De Ceunynck et al, 2013). However, such categorisation does not consider the full yielding process in which the road users involved need to interact with each other. Van Minnen and Braimaister (1994) 
also considered the manner of crossing in terms of taking and getting priority. They acknowledged that such definitions are only useful if the difference between taking and getting can be objectively identified. However, in these definitions 'taking' and 'getting' do not align with the priority rule. Therefore, in section 3.1, their definitions of yielding types were further developed. The difference between 'taking' and 'getting' priority was established on the basis of the motorist's location. Further research is needed to determine if distance is a reliable objective measurement in this regard.

The number of observation locations in this research was limited. However, this is not uncommon practice. Van Haperen (2016) conducted a scoping review on behavioral observation studies conducted in scientific literature and found that studies evaluating the effect of a certain measure used only four testing sites in $60 \%$ of the total amount of studies. For two locations even this figure was $50 \%$. Also compared to other scientific studies, the amount of interactions should be sufficient, even though a larger sample size would have been preferable. Finally, althought this study included an evaluation of the priority ruling, its main aim was to improve the understanding of the yielding process, using in-depth observations of yielding occurences.

This research used semi-automated video analysis software to analyse road user behavior. Although this is still a rather time consuming process, it allows for accurate, reliable and objective analyses of road user behavior at the micro level. Other more conventional techniques (e.g., human observers or inductive loops) do not enable data analyses at the same level of detail achieved in this study.

The analysis of yielding behavior showed that the location with motorist priority and a zebra crossing had deviating results when cyclists' crossing from right to left occured. A high proportion of incorrect cycling behavior was observed at this location; in $68 \%$ of cases, the cyclist arrived at the crossing facility while cycling in the opposite (illegal) direction. This percentage was much lower for the other locations $(27 \%, 17 \%$ and $0 \%)$. The findings indicate that drivers might not expect cyclists to approach from this direction, which is reflected by a lower proportion of drivers' speed reduction. However, the privacy legislation did not allow us to film inside the car, making it impossible to examine if searching behavior was an influence.

The safety evaluation showed that for 93 out of 1,366 $(<7 \%)$ interactions, a TA value could be calculated, of which $43(3 \%)$ were labelled serious conflicts (based on a threshold level of 24 in the Swedish Traffic Conflict Technique). For the $\mathrm{TTC}_{\min }$ indicator, the percentage of serious conflicts was even lower: only $2 \%(\mathrm{n}=23)$ based on a threshold value of 1.50 seconds. Linear regression models for both indicators revealed that the priority rule had no statistically significant influence on cyclists' safety at the 0.05 level. However, the $\mathrm{TTC}_{\min }$ indicator found lower values for locations with motorist priority $(\mathrm{p}=0.094)$, hinting that these locations might experience more safety critical values. The descriptive analysis indicated that cases where motorists had priority and cyclists crossed from right to left (from the viewpoint of the driver) resulted in more serious conflicts (although this could not be confirmed at the 5\% significance level). Further research and more data and testing sites might confirm that locations with motorist priority have more safety critical events.

\section{CONCLUSIONS}

The most important findings of this research are:

- Independent of the priority rule, cyclists cross first at CRTLs in the majority of cases.

- During most interactions at locations where cyclists should yield, motorists give their priority away willingly. 
- Although the $\mathrm{TTC}_{\min }$ and TA indicator measure different conflict characteristics, strong correlations were found between them $\left(r^{2}>0.83\right.$ when TA values are considered and $r^{2}>$ 0.60 when TA severity levels are taken into account).

- A possible influence of the priority rule on conflict severity was found.

- Although not significant, the two safety indicators both suggested that the priority rule favouring motorists have more serious conflicts when cyclists cross from right to left (from the perspective of the approaching driver).

\section{ACKNOWLEDGEMENTS}

This research was carried out within the framework of the Policy Research Centre on Traffic Safety with the support of the Flemish government and was partly supported by a grant from the Research Foundation Flanders. The content of this paper is the sole responsibility of the authors.

\section{REFERENCES}

AASHTO (2011). The Green Book: A Policy on Geometric Design of Highways and Streets. Washington DC, ISBN 978-56051-508-1

Amundsen, F.H. \& Hydén, C. (1977) Proceedings: First Workshop on Traffic Conflicts, Oslo 1977. Institute of Transport Economics, Oslo/Lund Institute of Technology, 1977.

Autey, J., Sayed, T., \& Zaki, M. H. (2012). Safety evaluation of right-turn smart channels using automated traffic conflict analysis. Accident Analysis \& Prevention, 45(0), 120-130. http://doi.org/10.1016/j.aap.2011.11.015

Bertulis, T., \& Dulaski, D. M. (2014). Driver Approach Speed and Its Impact on Driver Yielding to Pedestrian Behavior at Unsignalized Crosswalks. Transportation Research Record: Journal of the Transportation Research Board(2464), pp 46-51. Retrieved from http://dx.doi.org/10.3141/2464-06

Björklund, G.M. and Åberg, L. (2005) Driver Behavior in Intersections: Formal and Informal Traffic Rules. Transportation Research Part F: Traffic Psychology and Behavior 8(3), pp 239-253, doi:10.1016/j.trf.2005.04.006.

De Ceunynck, T., Polders, E., Daniels, S., Hermans, E., Brijs, T. and Wets, G. (2013) Road Safety Differences Between Priority-Controlled Intersections and Right-Hand Priority Intersections. Transportation Research Record 2365, pp. 39-48. doi:10.3141/2365-06.

De Ceunynck, T., Daniels, S., Polders, E., Vernyns, L. (2015) Geobserveerd voorrangsgedrag bij fietsoversteken op rotondes met vrijliggende fietspaden. Steunpunt Verkeersveiligheid 2012-2015. 27p, RA-2015-007, Diepenbeek.

Dixon, K. K., Hibbard, J. L., \& Nyman, H. (1999). Right-Turn Treatment for Signalized Intersections. In Transportation Research Circular E-C019: Urban Street Symposium: Conference Proceedings. Washington, D.C.

El-Basyouny, K., \& Sayed, T. (2013). Safety performance functions using traffic conflicts. Safety Science, 51(1), 160-164. http://doi.org/10.1016/j.ssci.2012.04.015

Fitzpatrick, K., Schneider, W., \& Park, E. (2006). Operation and safety of right-turn lane designs. GEOMETRIC DESIGN AND THE EFFECTS ON TRAFFIC OPERATIONS 2006, 55-64.

Herslund, M.-B., \& Jørgensen, N. O. (2003). Looked-but-failed-to-see-errors in traffic. Accident Analysis \& Prevention, 35(6), 885-891. http://doi.org/10.1016/S0001-4575(02)00095-7

Hydén, C. (1987). The development of a method for traffic safety evaluation: The Swedish Traffic Conflicts Technique. Lund Institute of Technology, Lund, Sweden.

Kraay, J.H., van der Horst, A.R.A, \& Oppe, S., (2013) Manual conflict observation technique DOCTOR. SWOV, p86, report 2013-I, Voorburg. 
Laureshyn, A., de Goede, M., Saunier, N., \& Fyhri, A. (2016). Cross-comparison of three surrogate safety methods to diagnose cyclist safety problems at intersections in Norway. Accident Analysis \& Prevention 105, 11-20. 10.1016/j.aap.2016.04.035

Polders, E., Daniels, S., Hermans, E., Brijs, T., \& Wets, G. (2015). Crash patterns at signalized intersections. Transportation Research Record: Journal of the Transportation Research Board, 2514, 105-116. http://dx.doi.org/10.3141/2514-12

Potts, I. B., Harwood, D. W., Bauer, K. M., Gilmore, D. K., Hutton, J. M., Torbic, D. J., Barlow, J. M. (2011). Design Guidance for Channelized Right-Turn Lanes (No. NCHRP Project 03-89). Midwest Research Institute.

Potts, I., Bauer, K., Torbic, D., \& Ringert, J. (2013). Safety of Channelized Right-Turn Lanes for Motor Vehicles and Pedestrians. Transportation Research Record: Journal of the Transportation Research Board, 2398, 93-100. http://doi.org/10.3141/2398-11

Sacchi, E. and Sayed, T. (2013) A comparison of collision-based and conflict-based safety evaluations: The case of right-turn smart channels. Accident Analysis and Prevention 59, pp. 260-266

Sakshaug, L., Laureshyn, A., Svensson A. and Hydén, C. (2010) Cyclists in roundabouts-Different design solutions. Accident Analysis and Prevention 42(4), pp. 1338-1351

Sayed, T., Zein, S., 1999. Traffic conflict standards for intersections. Transportation Planning and Technology 22, 309-323

Sayed, T., Zaki, M. H., \& Autey, J. (2013). Automated safety diagnosis of vehicle-bicycle interactions using computer vision analysis. Safety Science, 59(0), 163-172. http://doi.org/10.1016/j.ssci.2013.05.009

Shbeeb, L. (2000). Development of a traffic conflicts technique for different environments. A comparative study of pedestrian conflicts in Sweden and Jordan (Doctoral dissertation). Bulletin 188, Lund Institute of Technology, Sweden.

Svensson, A. (1998) A Method for Analysing the Traffic Process in a Safety Perspective (Doctoral dissertation). Department of Traffic Planning and Engineering, Lund Institute of Technology, Lund, Sweden.

Svensson, A. and Hydén, C. (2006). Estimating the severity of safety related behavior. Accident Analysis and Prevention, 38, pp. 379-385

T-Analyst, 2014. Software for semi-automated video processing. Retrieved from www.tft.lth.se/video/co-operation/software/.

Van Haperen, W. "Review of current methods for VRU safety (Appendix 5)" In: Review of current study methods for VRU safety, 2016, 60p.

Van Minnen, J., \& Braimaister, L. (1994). De voorrangsregeling voor fietsers op rotondes met fietspaden - Een studie naar de meest geschikte voorrangsregelingen voor rotondes, met speciale aandacht voor de fietsers op vrijliggende fietspaden (No. R-94-73). Leidschendam, The Netherlands: Stichting Wetenschappelijk Onderzoek Verkeersveiligheid SWOV. 